\title{
Real-Time Feed-backed Anode Power Supply for 170GHz gyrotron in KSTAR
}

\author{
Bong-Jun Seok ${ }^{1}$, Il-kun Ahn ${ }^{1}$, Seung-kyo Lee ${ }^{1}$, Eun-yong Shim ${ }^{1}$, \\ Young-soon Bae ${ }^{2}$, Mi Joung ${ }^{2}$, Jin-Hyun Joung ${ }^{2}$ \\ ${ }^{1}$ Dawonsys company,227, Gyeonggihwagidae-ro, Siheung-si, Gyeonggi-do 429-850, Korea \\ ${ }^{2}$ National Fusion Research Institute, Gwahangno 113, Yuseong-gu, Daejeon 305-333, Korea
}

\begin{abstract}
MW (66 kV/55 A) high voltage power supply system was developed for the $170 \mathrm{GHz}$ ECH\&CD system in KSTAR. It consists of the cathode power supply (CPS), anode power supply (APS), and body power supply (BPS).Currently, modulation frequency of APS was limited to less than $1 \mathrm{kHz}$ due to the parasitic capacitance of Zener diode circuit including gyrotron. In order to solve these lacks of controllability and high frequency modulation of APS, the existing APS is replaced by a new type of APS and it is tested for KSTAR $170 \mathrm{GHz}$ gyrotron system. This paper presents the new APS design and characteristics and the test results for $170 \mathrm{GHz}$ gyrotron in KSTAR ECH system.
\end{abstract}

\section{Introduction}

In A 3.6 MW (66 kV/55 A) high voltage power supply system was developed for the $170 \mathrm{GHz}$ ECH\&CD system in KSTAR. It consists of the cathode power supply (CPS), anode power supply (APS), and body power supply (BPS).

Currently, modulation frequency of APS was limited to less than $1 \mathrm{kHz}$ due to the parasitic capacitance of Zener diode circuit including gyrotron. The APS consists of fixed resistors and many series connections of Zener diodes. Each Zener diode has the voltage holding of $200 \mathrm{~V}$. The input of APS is connected to the output of CPS with the reference of the ground potential. The cathode-anode voltage is not actively regulated following the fluctuation of the cathode voltage. In order to solve these lacks of controllability and high frequency modulation of APS, the existing APS is replaced by a new type of APS and it is tested for KSTAR $170 \mathrm{GHz}$ gyrotron system.

The new APS is composed of a Cap Charger Power Supply (CCPS), High Voltage Switch (HVS) Tank. The CCPS has specification of rated energy at maximum $35 \mathrm{~kJ} / \mathrm{S}$ and the control frequency at $20 \mathrm{kHz}$. The storage energy of the CCPS is supplied to cathode-anode of gyrotron pursuant to HVS tank. The HVS consists of a on/off switch and a discharging switch which are made by parallel and series connections of many MOSFET fast solid-state switch of which switching on-off time is less than 1 microsecond.

This configuration reduced significantly the total parasitic capacitance between cathode and anode in gyrotron. The developed new APS has specification of rated voltage at $0 \sim 50 \mathrm{kV}$, rated current at maximum $1 \mathrm{~A}$. Also, the voltage output is regulated with stability of $0.3 \%$ and the modulation is possible to up to $10 \mathrm{kHz}$ with the rising and falling time less than ten microseconds.

The output of CCPS is rapidly feedback controlled by real time control board using analog comparator circuit. Since the CCPS reference (common to chassis) is connected to the CPS output, the cathode-anode voltage will be supplied with constant level. In addition, the active cathode-anode voltage control capability will be applicable for the active beam current control to overcome the beam emission cooling effect for the long pulse operation of the gyrotron

This paper presents the new APS design and characteristics and the test results for $170 \mathrm{GHz}$ gyrotron in KSTAR ECH system

\section{New APS power supply}

The new Anode Power is composed of Capacitor Charger Power Supply, High Voltage Switch.Capacitor. Charger Power Supply characteristic is as follow :

- Rated energy at maximum $35 \mathrm{~kJ} / \mathrm{S}$.

- Control frequency at $20 \mathrm{kHz}$.

- Rated voltage/current at 0 50kV/1A.

- Voltage regulation with stability of $\pm 0.3 \%$

\footnotetext{
$\bar{a}$ Corresponding author: bongjoon9@ dawonsys.com
} 
Capacitor Charger Power Supply characteristic is as follow :

- Rated voltage/current at $60 \mathrm{kV} / 1 \mathrm{~A}(\max 100 \mathrm{kV} / 30 \mathrm{~A})$

- Has On/off switch and discharging swtich

- Modulation with frequency of up to $10 \mathrm{kHz}$

- Switch on/off time less than one microseconds

Fig1 shows the cap. charger power supply and Fig2 shows the inside of high voltage swtich

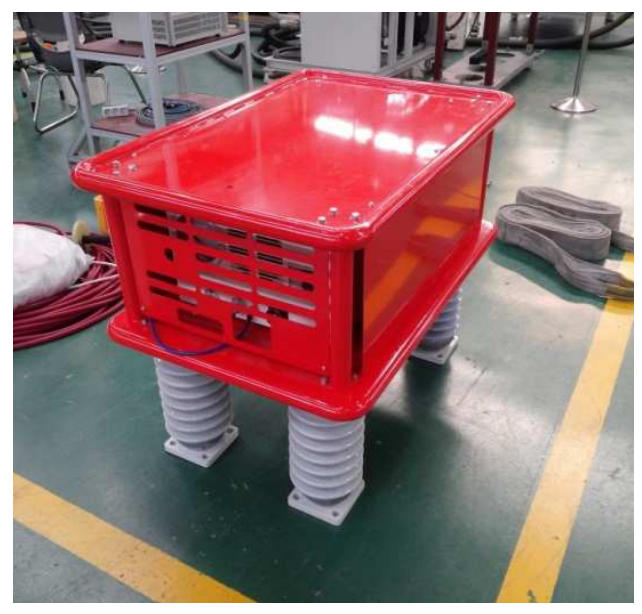

Fig 1 Cap. Charger Power Supply

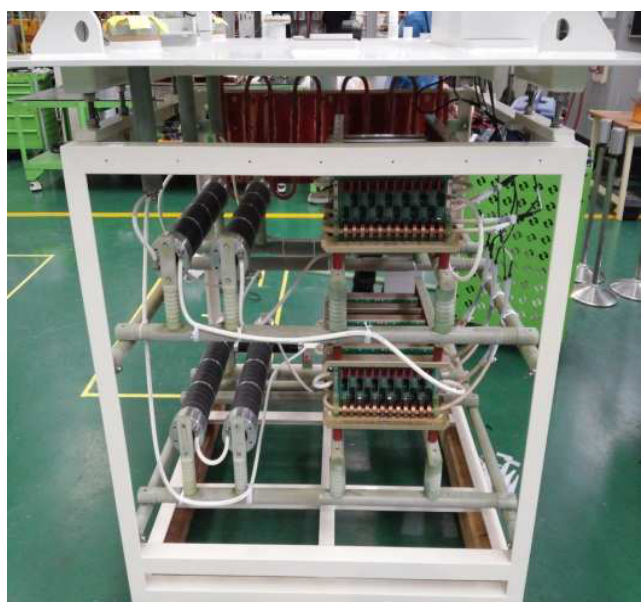

Fig 2. Inside of the High Voltage Switch

\section{Single Line Diagram}

The single Line Diagram is shown in Fig 5. The Incoming is $22.9 \mathrm{kV}$. There is $\mathrm{VCB}$ for the $22.9 \mathrm{kV}$ and the transformer which makes the voltage down to $6.6 \mathrm{kV}$. the $6.6 \mathrm{kV} \mathrm{VCB}$ is installed after the transformer. The VCS with pre-charging VCS and pre-charging resistor in parallel for the HV chopper and the LV chopper is used. After VCS, there are 4set of HV chopper transformers and 1set of LV chopper transformer that supply the proper voltage for the choppers. The HVDC generator consists of 20 high voltage (HV) choppers and 12 low voltage (LV) choppers. The HVS is installed at the end stage of output for the openning the gyrotron from the $\mathrm{HV}$ circuit at the arcing. This output is connected to the cathode of gyrotron.

The developed new APS has specification as rated voltage at $0 \sim 50 \mathrm{kV}$, rated current $1 \mathrm{~A}$. The modulation is possible to up to $10 \mathrm{kHz}$. The ground potential of APS is connected to the CPS output. Thus, the new APS is floating from ground level. Therefore, the new APS is able to control the beam current regardless of the voltage droop of CPS.

The BPS consist of high voltage source and high voltage switches. It is connect to the body and collector.and supply the positive voltage. The resistor, Rs is connected at output stage. The function of Rs is the surge suppression at the arc situation. In Fig3, the CPS is full chopper type power supply. It consist of 20set HV choppers and 12set LV choppers. All chopper is connected in series each other. The chopper uses the two kinds of IGBTs. The $6500 \mathrm{~V} / 400 \mathrm{~A}$ IGBT is for $\mathrm{HV}$ chopper. The $1200 \mathrm{~V} / 400 \mathrm{~A}$ IGBT is for LV chopper. The output of $\mathrm{HV}$ chopper and LV chopper is $3 \mathrm{kV}$ and $0.5 \mathrm{kV}$. The total output voltage is $66 \mathrm{kV}$. The overall $\mathrm{ECH}$ system is shown in Fig 4.

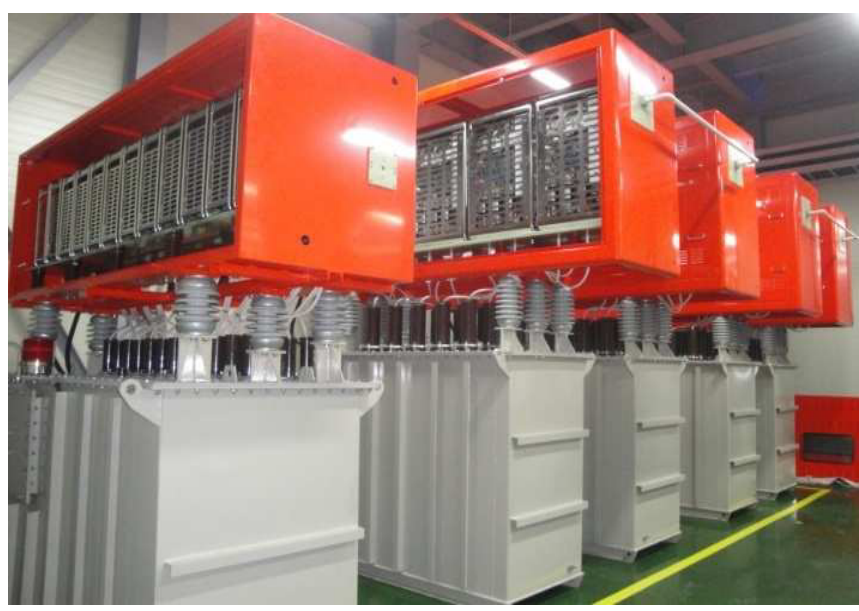

Fig 3. CPS Choppers

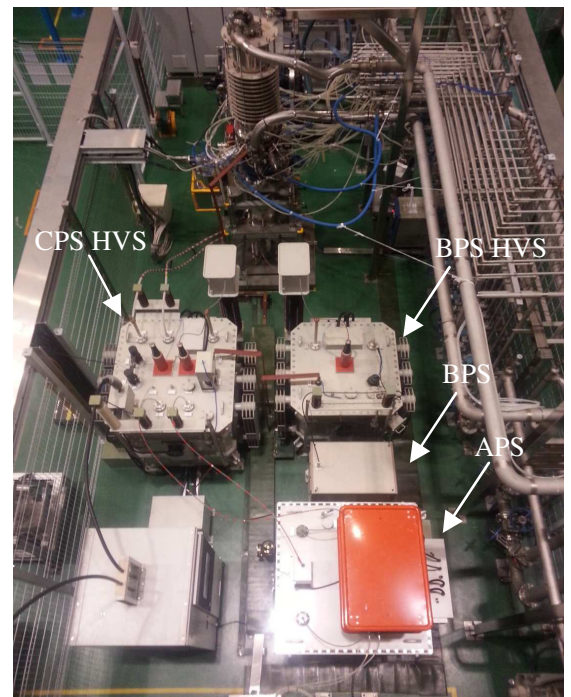

Fig 4. 170GHz ECH system(APS, BPS, HVS) 


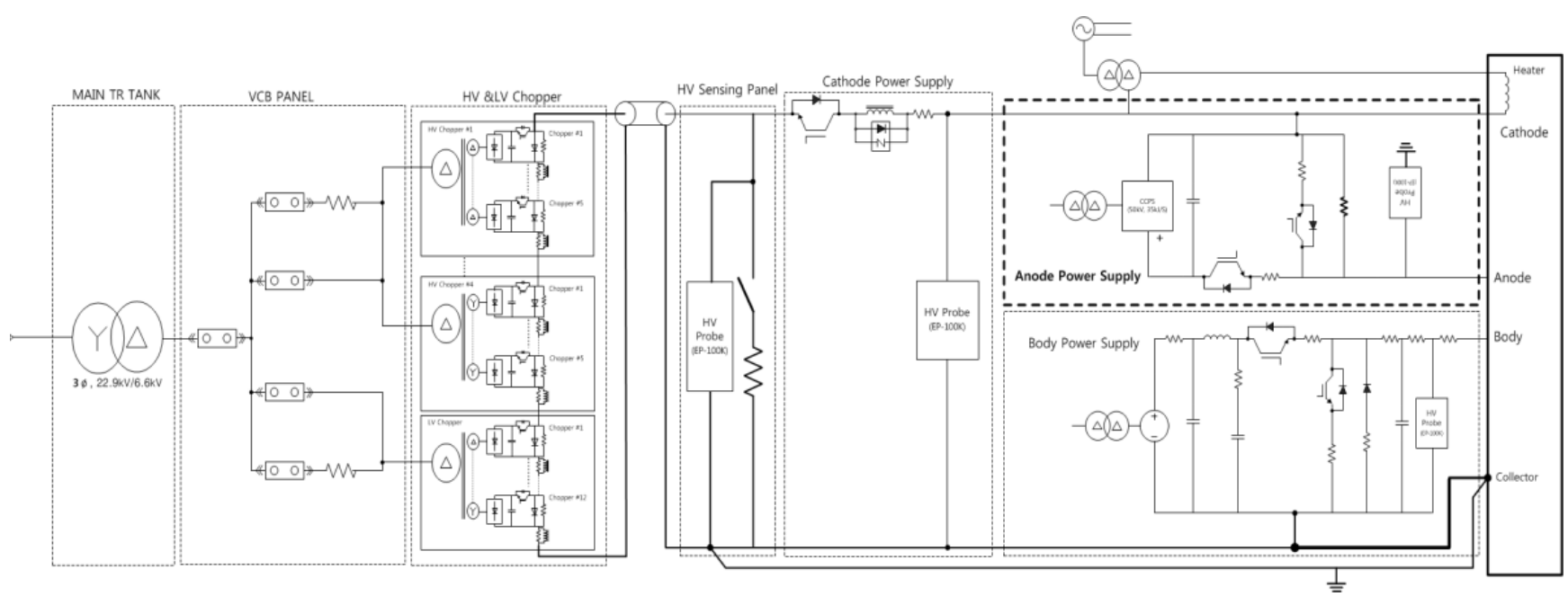

Fig 5. Single Line Diagram

\section{Simulation}

The simulation was using PSIM. The new APS in ECH system is verified the system stability. The overall ECH system with the new APS is shown in Fig 6.

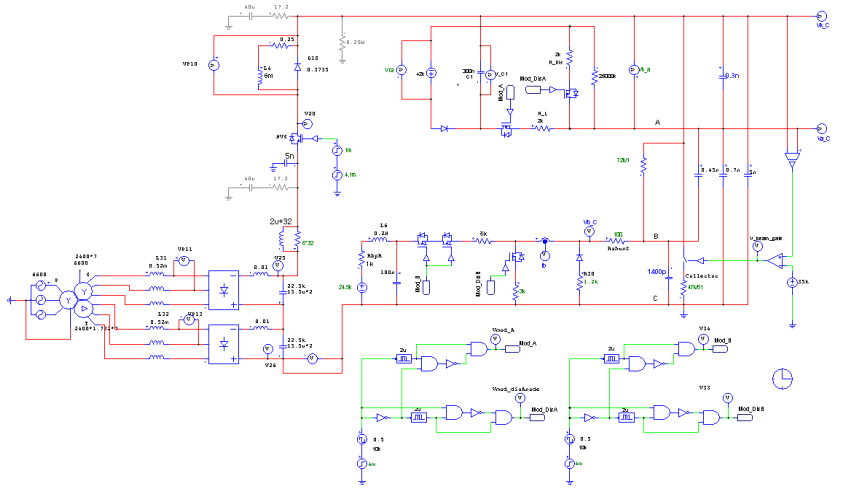

Fig 6. Overall 170GHz ECH system.

\subsection{Simulation results}

The new APS Simulation results are shown in Fig 7.
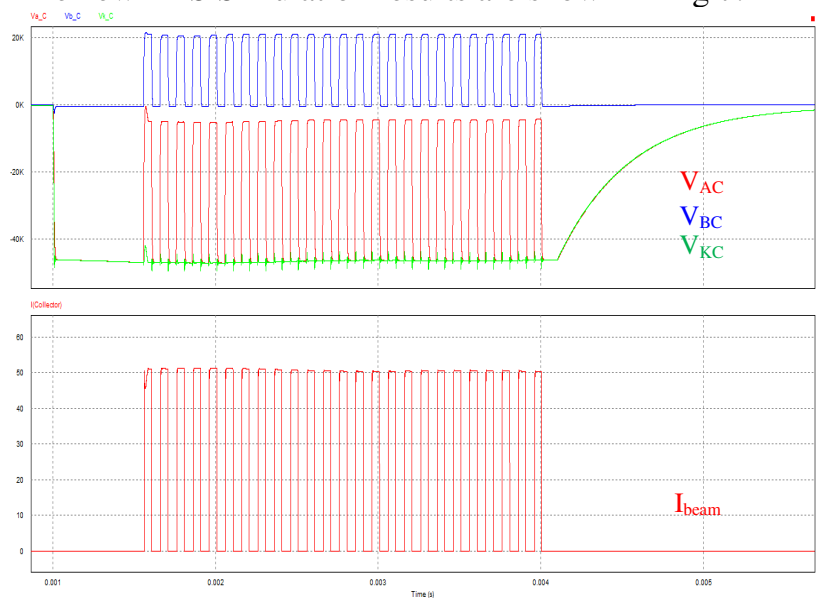

Fig 7. Output waveforms

\section{Experimental}

\subsection{Shop test}

In order to have a shop test, parasitic capacitance in gyrotron of between cathode and anode had to calculate.

The parasitic capacitance of the gyrotron was calculated to the experimental data. When output voltage of APS was discharged, using time constant is able to calculate. Thus, we was chosen as $1.2 \mathrm{nF}$. For the performance test of the new APS, we were tested in rising and falling time, modulation, stability, load protection test(short circuit test). The experimental results are from Fig 8. to Fig11. The rising and falling time of the new APS are shown in Fig8.

In Fig 8, the rising and falling time was less than 7 microseconds. After checking the rising and falling time, the modulation performance of new APS was checked. The modulation of the new APS was up to $10 \mathrm{kHz}$ in Fig 9. The stability of the new APS was checked from the long pulse test. The result was \pm 0.3 percent in Fig 10 . Finally, we were tested for load protection. In Fig11, When the arc was occured, the HVS off delay time of the new APS is less than 100ns.

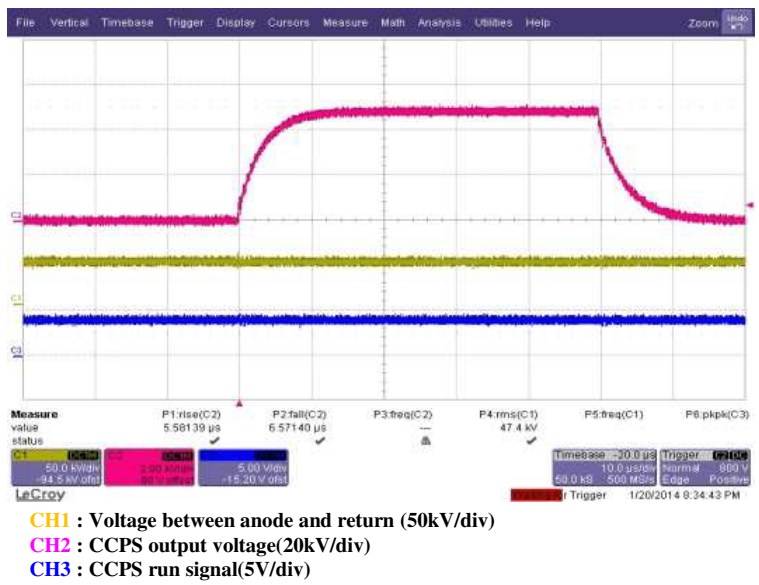

Fig 8. Rising and falling time of APS 


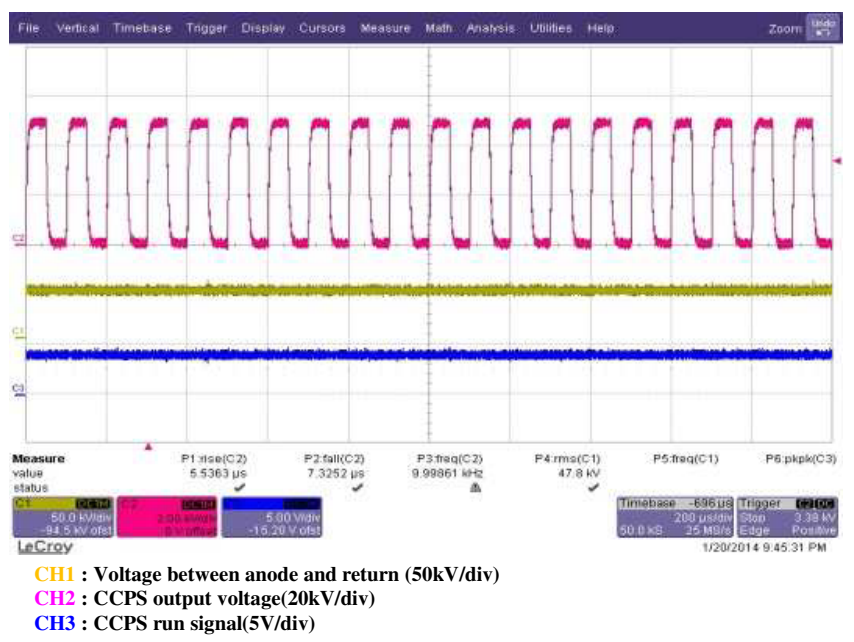

Fig 9. Modulation at $10 \mathrm{kHz}$ for $\operatorname{Load}($ Cap. $1.2 \mathrm{nF})$

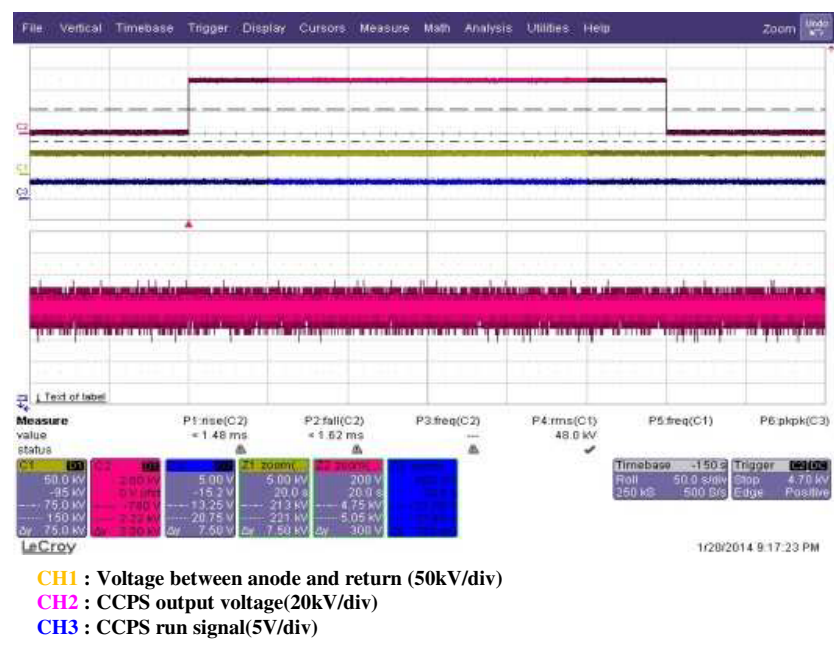

Fig 10. The stability of APS

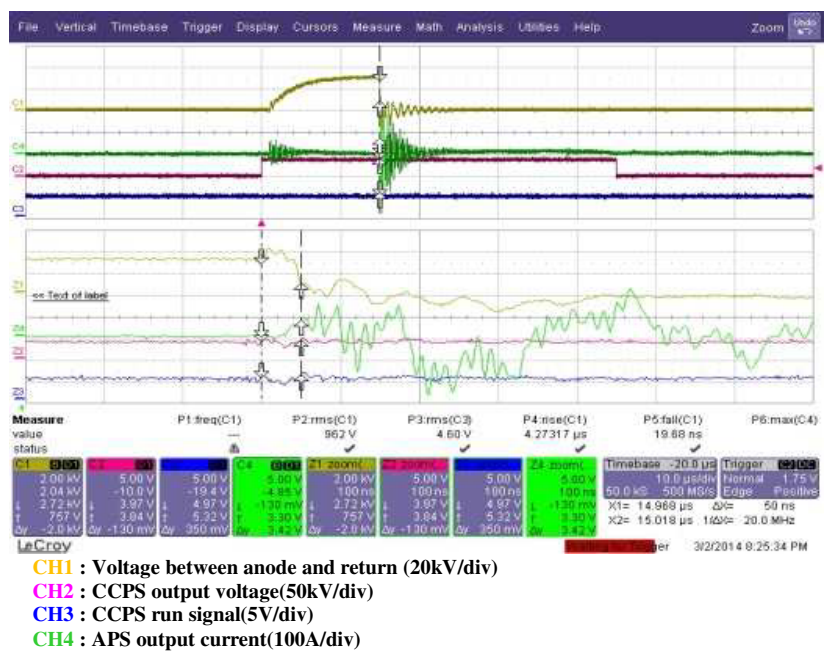

Fig 11. Short circuit test of APS

\subsection{Site test}

After the new APS was verified to performance in shop test, the new APS has tested in site. First, the new APS was demonstrated to the dummy load.
The new APS was modulated to up to $5 \mathrm{kHz}$. The modulation waveforms of the new APS are shown in Fig 12. After the dummy load test, the ECH system with new APS has connected to the gyrotron. The new APS has tested to modulation performance at $100 \mathrm{~Hz}$

The results are shown in Fig 13. The zero to flat top time was approximately ten micro seconds.

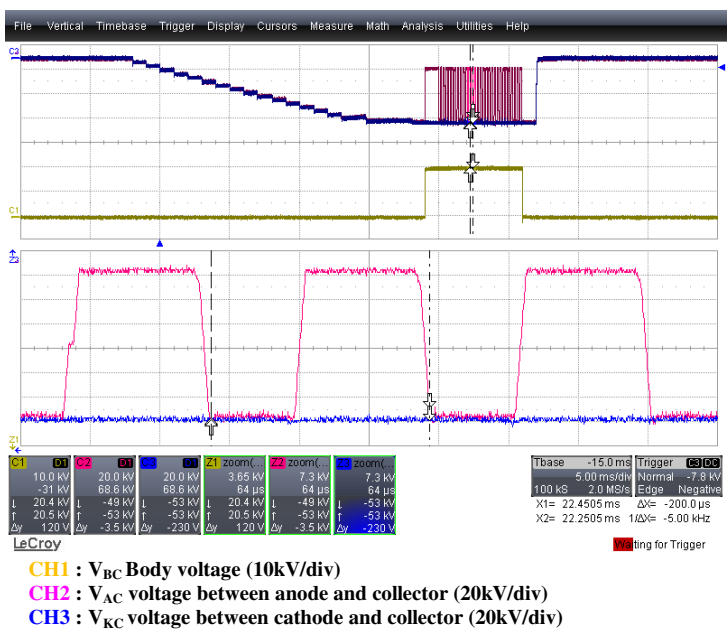

Fig 12. Dummy Load

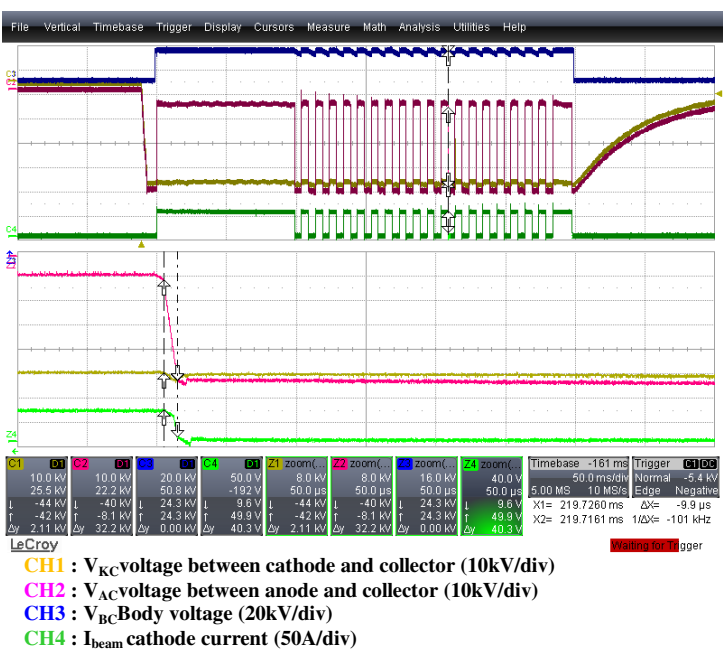

Fig 13. Gyrotron Load

\section{Conclusion}

The new anode power supply has a large number of outstanding features :

- The output of CCPS is rapidly feedback controlled by real time control.

- The cathode-anode voltage will be supplied with constant level.

- The APS modulation is possible to up to $10 \mathrm{kHz}$ with the stability of $\pm 0.3 \%$.

- The rising and falling time less than ten microseconds.

In conclusion, the new anode power supply was found to be suitable for gyrotron application. 
The additional experimental test plan :

- The modulation operation with gyrotron of a new APS up to $5 \mathrm{kHz}$.

- $\quad$ Long pulse operation (> $30 \mathrm{~s}$ ) with 1MW RF output.

- APS control from external signal (PCS:Plasma Control System). 